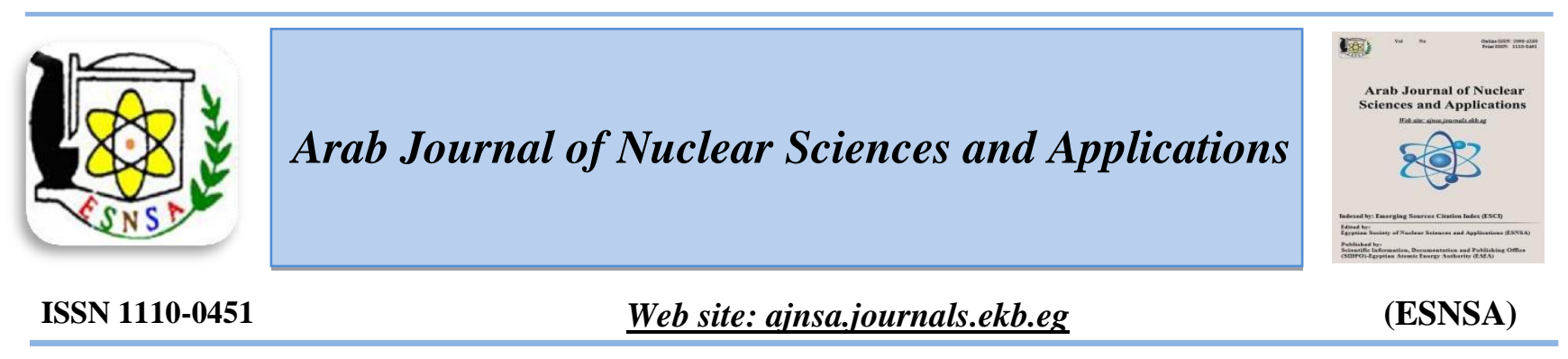

\title{
Optical Absorption Spectroscopy of the Blackberry Dye Applied in Solar Cell Sensitizers and Gamma Radiation Effects
}

\author{
Maged A. F., Amin M.*, Osman H. *, and Nada L.A.M. \\ Solid State and Electron Accelerators Department, National Center for Radiation Research and Technology, \\ (NCRRT), Atomic Energy Authority, Cairo, Egypt \\ *Physics Department, Faculty of Science, Cairo University, Giza, Egypt
}

Received $19^{\text {th }}$ Jan. 2018 This paper is a part of natural dye solar cell project. The dye extracted from blackberry fruit is Accepted $14^{\text {th }}$ Feb. 2018 successfully used in the fabrication of natural dye sensitized solar cells (NDSSC). Blackberry dye extract is showed to contain anthocyanins which is an excellent light harvesting pigment needed for the generation of charge carriers for the production of electricity. A strong absorbance in the green region $(520 \mathrm{~nm})$ is observed for blackberry dye at $\mathrm{pH}$ 1. The color intensity of the blackberry dye is decreased with the gamma dose up to $5 \mathrm{kGy}$ and then saturation started. The high absorption range is found in blackberry dye 360-750 $\mathrm{nm}$. The absorption band edge value of the natural dye solutions of the blackberry is found to be $1.97 \mathrm{eV}$ from the maximum peak position (at wavelength $630 \mathrm{~nm}$ ). Tauc $\operatorname{gap}\left(E_{\mathrm{g}}\right)$ of the blackberry dye is found to be $1.96 \mathrm{eV}$ for direct transition. It is observed that the gamma dose up to $7 \mathrm{kGy}$ showed no significant effect on both absorption edge and Tauc gap of blackberry dye. The particles sizes range of the blackberry dye form the blackness pigment is found to be 0.6-3.0 and 0.41.0 microns in diameter before and after gamma radiation. The optimum conditions of NDSSC based on this study of Blackberry dye are found that $\mathrm{V}_{\mathrm{OC}}=0.5, \mathrm{~J}_{\mathrm{SC}}=0.7 \mathrm{~mA} . \mathrm{cm}^{-1}, \mathrm{FF}=0.5$, and $\eta \%=0.2$.

Keywords:Blackberry, Dyes,Optical,Gamma radiation

\section{Introduction}

Natural dyes are generally environmentally friendly and have many advantages over synthetic dyes. In recent years, the applications of natural dyes were subject to research studies due to their biodegradability and higher compatibility with the environment [1-5]. Anthocyanins, with their common structure shown in Fig. 1, are flavonoids commonly found in fruits, flower petals, and leaves and produce orange, red, violet, and blue colors [6-7]. Earlier studies show that anthocyanins are especially abundant in blackberry, bilberry, strawberry, raspberry, grape skin, and so on [8-12].

The semiconductor oxides used in DSSCs are wide band gap materials, which do not absorb in the visible region. The function of harnessing the solar light is carried out by the sensitizer molecules attached to their surface. The absorption spectrum of the optimum dye for DSSCs should cover the whole visible region and even part of the near infrared. In addition, the dye must have suitable anchoring groups, which firmly attach the molecule to the semiconductor oxide. The classic sensitizer dye employed in DSSCs is a ruthenium dye, which is usually referred to as $\mathrm{N} 3$, or in its partially deprotonated form (a ditetrabutylammonium salt) as N719 [13].

Adsorption of the dye to the mesoporous film is achieved by simple immersion of the nanocrystalline film in a solution of dye, which results in the conformal adsorption of a dye monolayer to the film surface. The monolayer of the sensitizer is adsorbed to the surface of the

Corresponding author: magedali@ hotmail.com

DOI: 10.21608 /ajnsa.2686.10043

(C) Scientific Information, Documentation and Publishing Office (SIDPO)-EAEA 
semiconductor by chemical bonding. The function of the sensitizers is to absorb the incident light, inject the excited electron into the semiconductor. By far, the highest efficiency of DSSCs sensitized by Ru-containing compounds absorbed on nanocrystalline $\mathrm{TiO}_{2}$ reached $11-12 \%$ [14]. It is expected that a reduction in the loss-in-potential to $500 \mathrm{mV}$ by well matching the energy levels at the interface of photoanode/sensitizer/electrolyte, and the further extension of the light harvesting region to $920 \mathrm{~nm}$ by using strongly absorbing sensitizers, the photoelectric conversion efficiency (PCE) of DSSCs can be boosted to 19\% [15-17]. Even if such DSSCs provided a relatively high efficiency, there are several disadvantages of using noble metals in them. Noble metals resources are extremely limited, hence, their production is very expensive, and in addition, they are nonenvironmentally friendly. On the other hand, organic dyes are not only cheaper, but also reported to reach power conversion efficiency as high as $9.8 \%$ [18].

In nature, fruit, vegetable, leaves, flowers, and algae contain several dyes which can be easily extracted and employed in dye sensitized solar cells. The use of natural pigments as sensitizing dye for the conversion of solar energy in electricity is interesting because, on one hand it enhances the economical aspect and, on the other, it has significant benefits from the environmental point of view. Natural pigments extracted from fruits and vegetables, such as anthocyanins, chlorophyll, and betalains are extensively investigated as sensitizers for DSSCs [19].

Dyes are colored, ionizing, aromatic organic compounds. Anthocyanins are one of the largest and most important groups of water soluble pigment found in most species of plant kingdom. They are accumulated in cell vacuoles and are largely responsible for diverse pigmentation from orange to red, purple, and blue in flowers and fruits. Their color (red, purple or blue) is changed with $\mathrm{pH}$. They belong to a parent class of molecules called Flavonoids [20]. Their functions in flowers, with bright red and purple colors, are adaptive for attracting pollinators. In photosynthetic tissues (such as leaves and sometimes stems), anthocyanins is shown to act as a sunscreen, protecting cells from high-light damage by absorbing blue-green and UV light, thereby protecting the tissues from photoinhibition, or high-light stress [20]. Fig. (1) shows some possible structures for different anthocyanins.

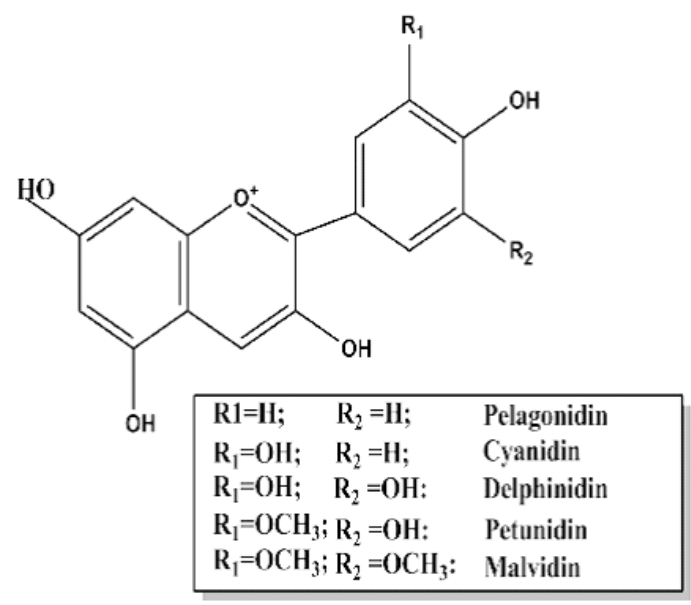

Fig. (1): Basic chemical structures of most abundant anthocyanins[21]

Pigments of pelargonidin and cyanidin derivatives produce red and purple color, respectively, whereas those of delphinidin show purple or blue color [21]. The anthocyanidins are hydroxylated and methoxylated derivates of phenyl-2benzopyrylium or flaylium salts, regarded as flavonoid compounds. Due to the presence of eight conjugated double bonds carrying a positive charge, anthocyanins are intensely red or orange under acidic conditions (below $\mathrm{pH}=2$ ), but at higher $\mathrm{pH}$, they are colorless and in alkaline conditions that change their color into bluish. The intensity and type of the color of anthocyanins are affected by the number of hydroxyl and methoxyl groups: if more hydroxyl groups, then the color goes toward a more bluish shade; if more methoxyl groups, then redness is increased [22]. Anthocyanins has a relatively small band gap (2.3 
$\mathrm{eV}$ ) as in the present study and absorbs in the visible region. The absorption spectra depend on $\mathrm{pH}$, at $\mathrm{pH}$ equal to or below 2, anthocyanins solutions show characteristic maxima of absorption, one in the ultraviolet region (approximately $260-280 \mathrm{~nm}$ ) and two in the visible region (approximately 415 and 490 - 540 $\mathrm{nm})$. The wavelengths of these absorbance peaks can differ slightly by a few nanometers among various anthocyanins, depending on structure of each anthocyanin. The maximum of absorption at 520 to $540 \mathrm{~nm}$ in the visible region is the most common wavelength used in the spectrophotometric measurement of total anthocyanins [23-24]. The solvent used for spectral determination affects slightly the position of the absorption bands; therefore it must be taken into consideration when comparing available data. Anthocyanins pigment is a low cost dye, easily available, easy to extract and applicable without additional purifications. All these reasons make anthocyanins vital alternative for synthetic dyes and most of other natural dyes. In this study, we have conducted blackberry juice. The construction of DSSC in the present project is a three-step process comprising: dye extraction, $\mathrm{TiO}_{2}$ paste application, and solar cell structure. This research work is conducted specifically to explore dye extraction of blackberry for dying the solar cells and to study the high energy effect.

\section{MATERIALS AND METHODS}

\section{Optical absorption}

The absorption spectra of the used dye samples are measured using Specord 210 plus UV-Vis spectrophotometer. The absorption data is taken from $200 \mathrm{~nm}$ to $1100 \mathrm{~nm}$ wavelength. A $10 \mathrm{~mm}$ quartz cuvett is used for the blackberry dye samples.

\section{Blackberry dye extraction}

The efficiency of a solar cell depends largely on the homogeneity of the natural dye extract. To select the dye having a good absorption in the visible region, fresh blackberry fruit, of Egyptian origin, is collected from the local market. First, the samples are washed with pure water, cut into smaller pieces and finely blended at room temperature in a shade to prevent pigment degradation. In order to achieve this desired homogeneity, blackberry samples are extracted through a very rigorous process. The blended samples are then filtered and the filtrate centrifuged to obtain a homogeneous dye extract.

\section{Buffer preparation}

The buffer is prepared at $\mathrm{pH}$ 1.0; by weighing 1.86 $\mathrm{g} \mathrm{KCl}$ into a beaker and adding distilled water to $980 \mathrm{~mL}$. Measure the $\mathrm{pH}$ and adjust $\mathrm{pH}$ to 1.0 $( \pm 0.05)$ with $\mathrm{HCL}$ (ca $6.3 \mathrm{~mL}$ ). Transfer to $1 \mathrm{~L}$ volumetric flask and dilute to volume with distilled water [25]. To prepare $\mathrm{pH} 4.5$; add $\mathrm{KCl}$ solution and water to $\mathrm{pH} 1.0$ until reached to the required value.

\section{Particle size analysis}

Dynamic Light Scattering (DLS) is an important tool for characterizing the size of nanoparticles in a solution. DLS measures the light scattered from a laser beam that passes through a colloidal solution and by analyzing the modulation of the scattered light intensity as a function of time. Dynamic light scattering system is used PSS-NICOMP 380-ZLS particle sizing system St. Barbara, California, USA.

\section{Gamma irradiation}

The Gamma cell 220 Excel ${ }^{60} \mathrm{Co}$ irradiation facilities (manufactured by Nordion, Canada) is a compact and self-contained irradiation unit offering an irradiation volume of approximately $6 \mathrm{~L}$. The absorbed dose rate of the cell during this project is found to be $2.1 \mathrm{kGy} / \mathrm{h}$.

\section{RESULTS AND DISCUSSION}

\section{Optical measurements of blackberry extract}

The extracted blackberry dye is characterized using UV-VIS spectrophotometer. UV-VIS spectra provided information about the frequencies at which the dyes absorb photons and also quantify the absorbed light. The spectra of dye extracted from blackberry at pH1; Fig. (2), show a strong absorbance in the green region $(520 \mathrm{~nm})$. The extract from blackberry mainly contains anthocyanins and one intense absorption band at $520 \mathrm{~nm}$ in the visible region is indicated the presence of this pigment. Anthocyanins reversibly change color with $\mathrm{pH}$ Fig. (2), which limits their effective use as food colorants for many applications, but also provides an easy and convenient method for measuring total pigment concentration [26]. The described method is a modification of methods originally described in Ref. [27-29]. 


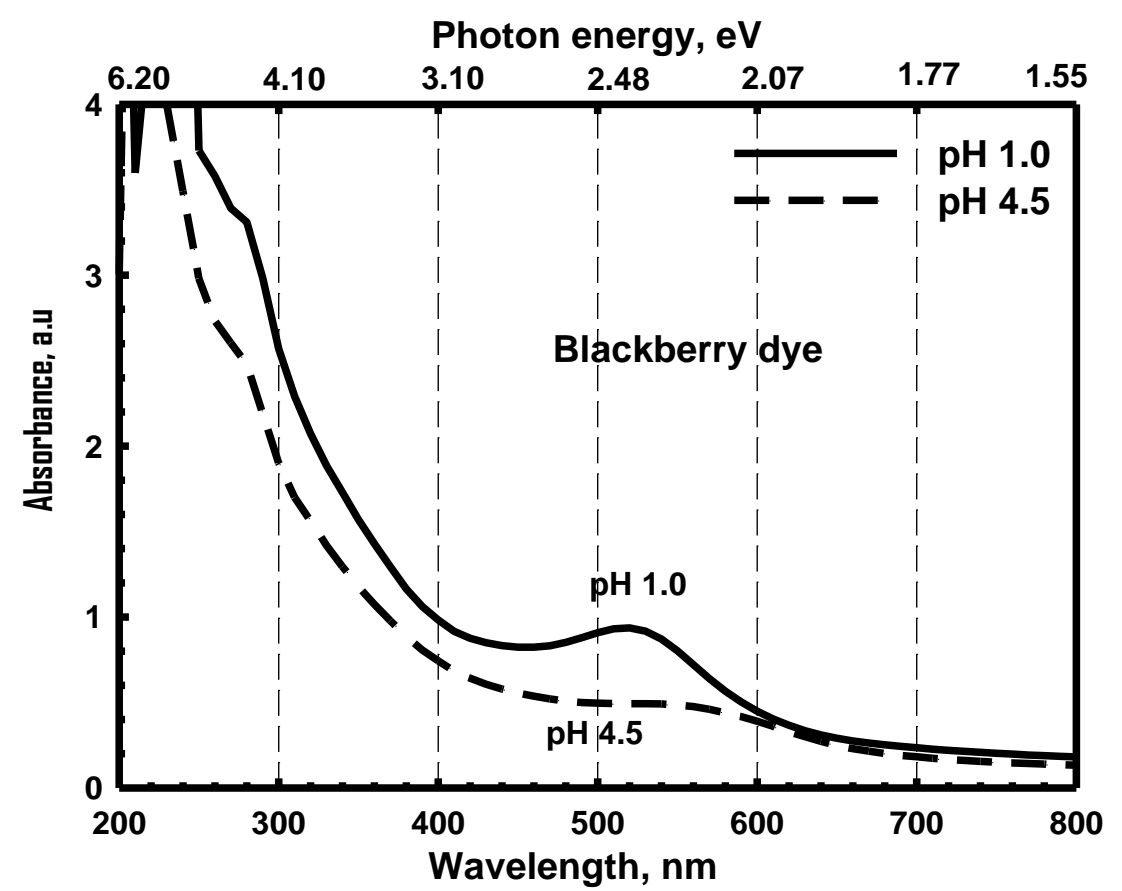<smiles></smiles>

Flavylium cation: orange to purple $\mathrm{pH}=\mathbf{1 . 0}$<smiles>[R]OC1=Cc2c(O[R])cc(O)cc2OC1(O)c1cc([R4])c(O)c([R4])c1</smiles>

Hemiketal forms: colorless $\mathrm{pH}=4.5$

Fig. (2): UV-Visible spectra of anthocyanins in pH 1.0 and 4.5 buffers, and the structures of the flavyliumcation (A) and hemiketal forms (B)

Samples are diluted with aqueous $\mathrm{pH} 1.0$ and 4.5 buffers and absorbance measurements are taken at the wavelength of maximum absorbance of the $\mathrm{pH} 1.0$ solution. The difference in absorbance between the two buffer solutions is due to the monomeric anthocyanin pigments. Fig. (2) shows the absorbance spectra and maxima of the extracted blackberry dye samples after $\mathrm{pH} 1.0$ adjustments. In acidic solution, blackberry dye appeared green, due to an intense band centered at $520 \mathrm{~nm}$ Fig. (2). This value is consistent with other [24]. The Anthocyanins are characterized by two absorption bands- Band I- 475-660 nm (Visible region) Band II- 275-280 nm (UV region). The actual color (Band I) depends on the number and position of hydroxyl and methoxyl groups. The broad peak of anthocyanins pigment is observed at $500-520 \mathrm{~nm}$ wavelength which indicated that anthocyanins pigment fall in the visible region with the absorbance 0.3-0.9 as shown in Fig. (2). The visible band is assigned to a $\pi-\pi^{*}$ charge transfer transition which results in a shift of the electronic charge density from the chromenium portion to the catechol end of the anthocyanins molecule. The graph of absorbance versus wavelength of raw extracted dye solution of blackberry with distilled water (solvent) as a reference before gamma radiation is shown in Fig. (3). The effect of gamma radiation up to $7 \mathrm{k} \mathrm{Gy}$ as a high energy is investigated on the blackberry extracted dye as shown in Fig. (3). It is observed that the color intensities decreased with the gamma 
dose up to $5 \mathrm{k}$ Gy and then the saturation started. It may be possible that electrons are removed from the electron cloud of chromophores, and then the loss in color occurred. Removal of electrons may cause the remaining electrons to revert to local orbits. Color in dyes is invariably explained as a consequence of the presence of chromophores. The technical term for color fading is photo degradation. There are light absorbing color bodies called chromophores that are present in dyes. The observed colors are based upon these chemical bonds and the amount of light absorbed in a particular wavelength.

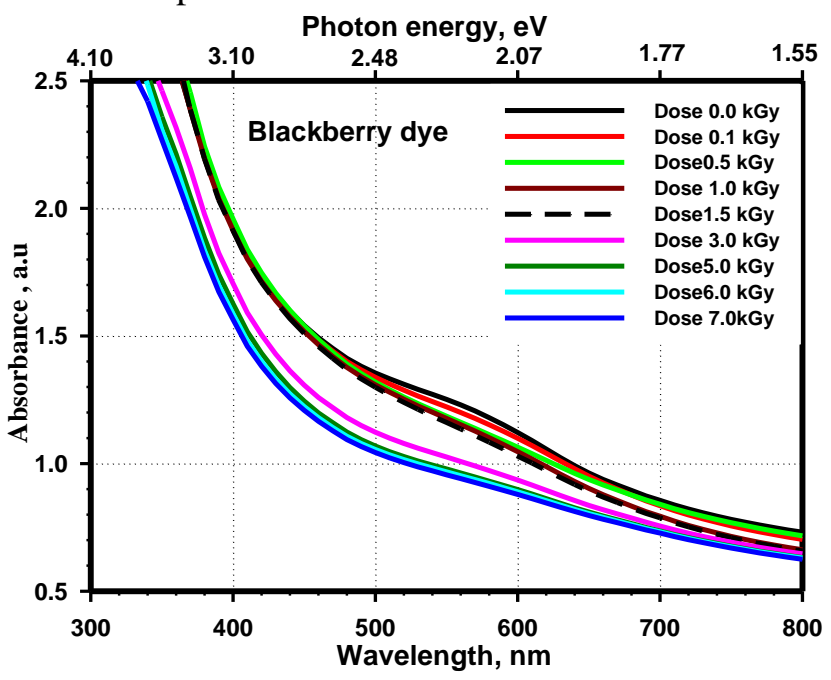

Fig. (3): The absorption spectra of blackberry dye under $\gamma$-radiation doses effects

Absorption band edge of blackberry dye

The transmittance spectrum of the blackberry dye solution is considered to investigate its optical properties at certain molarity and the plot of the transmittance vs. wavelength is showed in Fig. (4). The absorption band edge of blackberry dye and the UV-VIS spectrum of this sensitizer with its respective maximum wavelength are given in Table (1). As seen in Fig. (4) and its onset, the transmittance spectra of the dye solutions of the blackberry fruits until about $360 \mathrm{~nm}$ are not observed due to the high absorption of the dye

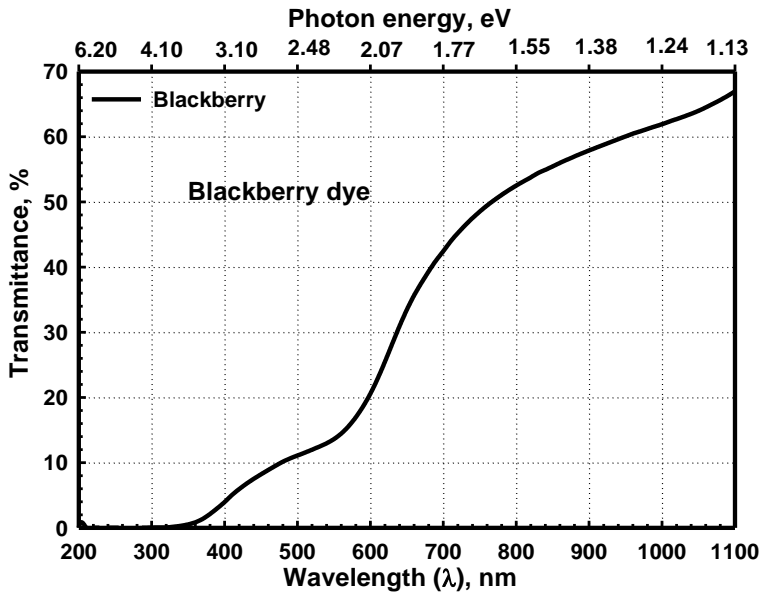

Fig. (4): The plot of the transmittance vs. $\lambda$ of blackberry dye at $0.0 \mathrm{kGy}$ solutions of the blackberry fruit, but the transmittance spectra of the dye solutions of the blackberry fruit sharply are increased in the range of about 360 and $800 \mathrm{~nm}$. After about $800 \mathrm{~nm}$, the transmittance spectrum of the blackberry dye solution is not observed again due to emitted red light at about $685 \mathrm{~nm}$ of the blackberry. In the visible region, the average transmittance $\left(\mathrm{T}_{\text {avg }}\right)$ value of the dye solutions of the blackberry is calculated and given in Table (1). It is observed that the high absorption range found in blackberry is $360-800 \mathrm{~nm}$, as clear from Fig. (4).

To estimate the absorption band edge of the natural dye solutions of the blackberry, the first derivative of the optical transmittance could be computed [30]. For this purpose, plot of $\mathrm{dT} / \mathrm{d} \lambda$ vs. wavelength is made for the natural dye solutions of the blackberry (Fig.5). The absorption band edge value of the natural dye solutions of the blackberry is calculated from the maximum peak position (at wavelength $630 \mathrm{~nm}$ ) and given in Table (1).

The absorption band edge of the dye solutions of the blackberry is found to be $1.97 \mathrm{eV}$. The dye of blackberry could be considered as reasonable liquid semiconductor and good light absorber in visible range. 
Tauc gap (optical energy gap) of blackberry dye Tauc gap, $E_{g}$ of optical transitions could be evaluated from the absorption spectrum using the Tauc relation [31]. Tauc gap, $\mathrm{E}_{\mathrm{g}}$ of the blackberry dye is found to be $1.96 \mathrm{eV}$ as shown in Fig. (6) which is in agreement with the value $(1.9 \mathrm{eV}$ and $2.7 \mathrm{eV}$ ) in the literature $[30,32-33]$ and given in Table (1). The approach of the first derivative of transmittance to wavelength promised to give good calculation for the absorption edge of any natural fruits solutions which is found roughly consistent to Tauc gap.

Gamma irradiation effects on optical absorption of blackberry dye

Gamma rays can break down the chemical bonds and thus fade the color in an object; it is of a bleaching effect. This color loss may be due to the removal of electrons from the charge cloud of chromophores as mentioned above. It is noticed that the color of the dye largely fades and with the appearance of some lees in dye solution after gamma irradiation (7 kGy) as shown in Fig. (3). The effect of gamma radiation on absorption edge and Tauc gap is investigated. It is observed that the gamma dose up to $7 \mathrm{kGy}$ showed insignificant effect on both absorption edge and Tauc gap of blackberry dye. This may be due to breaking chromophores group (color group) only, not the backbone molecule of anthocyanins.

\section{Particle size analysis of blackberry dye extract}

Small particles in suspension undergo random thermal motion known as Brownian motion. This random motion is modeled by the Stokes-Einstein equation. The equation given below is the most commonly used from for particle size analysis [34]. The diffusion coefficient $\boldsymbol{D}_{\boldsymbol{t}}$ is related to the radius of particles by Stokes-Einstein equation:

$$
\mathrm{D}_{\mathrm{Z}}=\frac{K_{B} T}{3 \pi \eta_{v} D_{t, a v g}}
$$

Where

$\mathrm{D}_{\mathrm{z}}$ is the hydrodynamic diameter (this is the goal: particle size)

$D_{t, \text { avg }}$ is the translational diffusion coefficient (by DLS)

$\mathrm{K}_{\mathrm{B}}$ is Boltzmann's constant (known)

$\mathrm{T}$ is thermodynamic temperature in Kelvin (solution temperature)

$\boldsymbol{\eta}_{\boldsymbol{v}}$ is dynamic viscosity (water $0.933 \mathrm{cp}$ )

Using dynamic light scattering, the sizes of the dye particles are analyzed before and after gamma radiation at dose $7 \mathrm{kGy}$ as displayed in Fig.(7a-b). The particles sizes range of the blackberry dye form the blackness pigment is found to be between 0.6-3.0 and 0.4-1.0 microns in diameter before and after gamma radiation, respectively. The frequency gives information about how far apart the particles are and how much of light bounces of the particles in the suspension. According to this data (shown in Fig.7), the dye will be well adsorbed unto the photo-anode of solar cell and still be able to absorb a high amount of sunlight. When the sizes of the particles in the dye are known, an understanding of how intensely the light will be absorbed and reflected by the particles in the dye could be attained. It is observed that the frequency started early after gamma irradiation as in Fig.(7b) than before gamma irradiation as shown in Fig. (7a). The percentage decrease of particles size after $\gamma$ irradiation is found to be $\sim 39 \%$. This might be due to the effect of gamma rays that cause breaking in chromophores as mentioned above. The size of the particles acts as crucial role to increase the efficiency of the cell and must measure for optimum output [6, 31, 35-36].

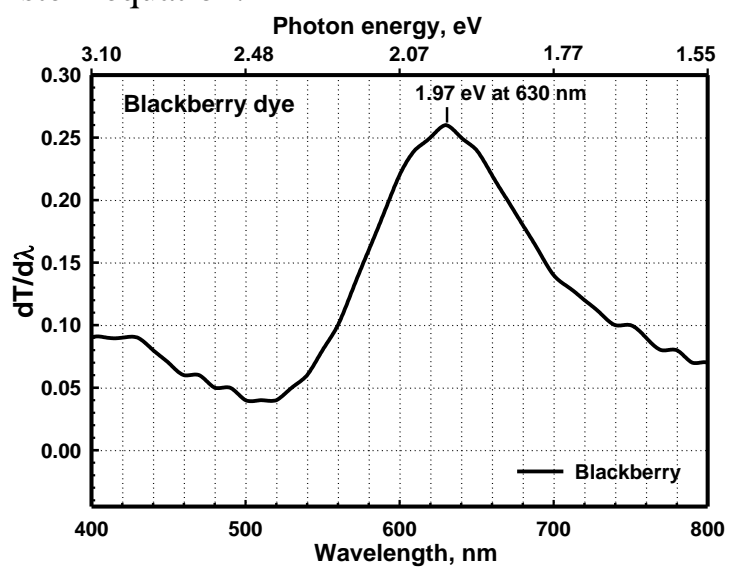

Fig. (5): the plot of $d T / d \lambda$ vs. $\lambda$ of the blackberry dye solution 
Table (1): The $T_{\text {avg }}$ (in the visible region), $\lambda_{\text {max.peak }}$, absorption band edge and

\begin{tabular}{|c|c|c|c|c|}
\hline Truits & $\begin{array}{c}\mathbf{T}_{\text {avg }} \\
(\%)\end{array}$ & $\begin{array}{c}\lambda_{\max }(\mathbf{n m}) \\
\text { of } \mathbf{1}^{\text {st }} \text { derivative }\end{array}$ & $\begin{array}{c}\text { Absorption } \\
\text { band edge, } \mathbf{e V}\end{array}$ & $\begin{array}{c}\text { Tauc gap, } \\
\mathbf{E}_{\mathrm{g}}, \mathbf{e V}\end{array}$ \\
\hline Blackberry & 25 & $\mathbf{6 3 0}$ & 1.97 & 1.96 \\
\hline
\end{tabular}

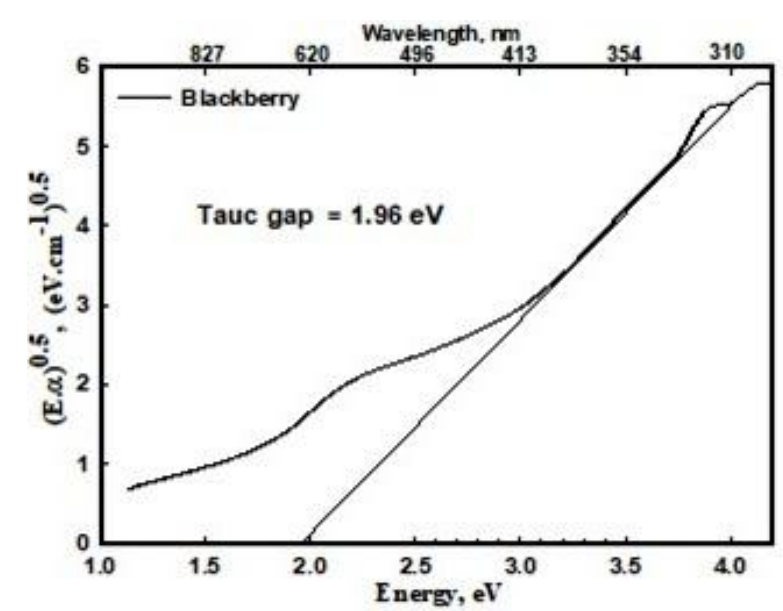

Fig. (6): The $(\alpha E)^{1 / 2}$ plot vs. the photon energy (E) of the Blackberry at 0.0 kGy
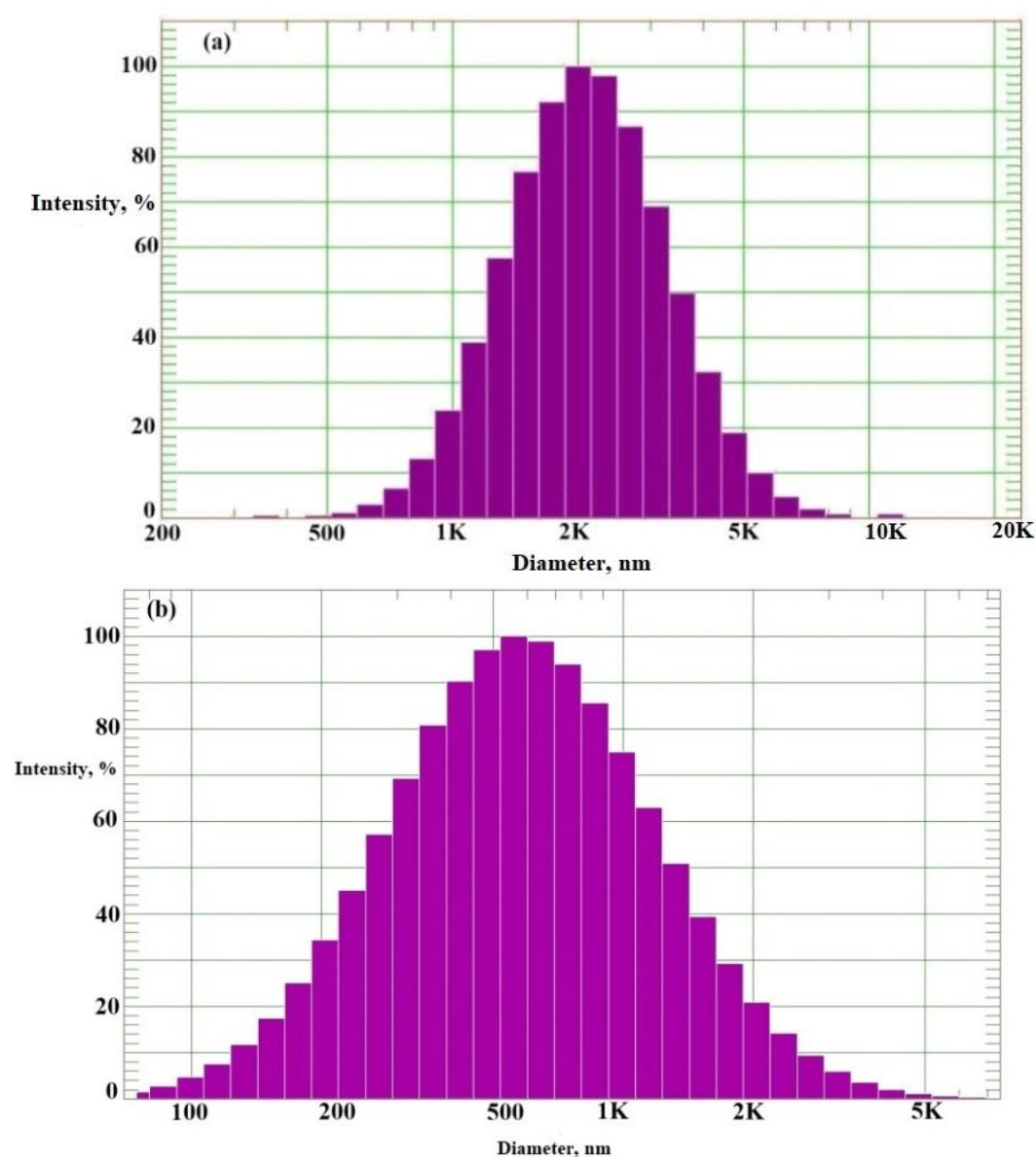

Fig. (7): Intensity-Weighted Gaussian distribution analysis of Blackberry dye: (a) before gamma radiation, and (b) after gamma radiation 


\section{Conclusion}

The efficiency of a solar cell depends largely on the homogeneity of the natural dye extract. The dye extracted from blackberry fruit is successfully used in the fabrication of natural dye sensitized solar cells (NDSSC). It is characterized using UVVIS spectrophotometer and dynamic light scattering. The spectra of dye extract from blackberry at $\mathrm{pH} 1$ showed a strong absorbance in the green region at $520 \mathrm{~nm}$. Anthocyanins reversibly change color with $\mathrm{pH}$. The effect of gamma radiation up to $7 \mathrm{kGy}$ as a high energy on the blackberry extracted dye showed that the colors intensities decreased. The transmittance onset of the dye solutions of the blackberry fruits until about $360 \mathrm{~nm}$ is not observed. The transmittance spectra of the dye solutions of the blackberry fruit sharply increased in the range of about 360-800 $\mathrm{nm}$. After about $800 \mathrm{~nm}$, the transmittance spectrum of the blackberry dye solution is not again observed. The absorption band edge of the dye solutions of the blackberry is $1.97 \mathrm{eV}$. Tauc gap, $E_{g}$ of the blackberry dye is $1.96 \mathrm{eV}$. The gamma dose up to $7 \mathrm{kGy}$ is showed insignificant effect on both absorption edge and Tauc gap of blackberry dye. The particles sizes range of the blackberry dye is found to be 0.6-3.0 and 0.4-1.0 microns in diameter before and after gamma radiation. The optimum conditions of NDSSC based on this study of blackberry dye are $\mathrm{V}_{\mathrm{OC}}=0.5$, $\mathrm{J}_{\mathrm{SC}}=0.7 \mathrm{~mA} \cdot \mathrm{cm}^{-1}, \mathrm{FF}=0.5$, and $\eta \%=0.2$.

\section{References}

1- Bechtold, T., Turcanu, A. nglberger, E.and Geissler,S. Natural dyes in modern textile dyehouses - how to combine experiences of two centuries to meet the demands of the future?, J. Cleaner Production, 11(5), 499-509 (2003).

2- Angelini, L. G., Bertoli, A. , Rolandelli, S., and Pistelli, L. Agronomic potential of ResedaluteolaL as new crop for natural dyes in textiles production, Industrial Crops and Products, 17(3), 199-207 (2003).

3- Tsatsaroni, E., Liakopoulou-Kyriakides, M. and Eleftheriadis, I. Comparative study of dyeing properties of two yellow natural pigments - effect of enzymes and proteins, Dyes and Pigments, 37(4), 307-315 (1998).

4- Huayin, W., Ping, Li. and Wenlong, Z., Dyeing of Silk with Anthocyanins Dyes Extract from Liriopeplatyphylla Fruits, Hindawi Publishing Corporation, J. Textiles, Vol. 2014, Article ID 587497, 9 pages(2014).
5- Giuseppe, C., Gaetano, D. M., Stefano, C., Silvia, C., Roberto A. and Carlo A. B., Natural dye senstizers for photoelectrochemical cells, Energy Environ. Sci., 2, 1162-1172 (2009).

6- Jackman, R. L., Yada, R. Y., Tung, M. A. and Speers, R. A. Anthocyanins as food colorants-a review, J. Food Biochemistry, 11(3), 201-247 (1987).

7- Andersen, Ø. M. and Jordheim, M. Anthocyanins in Encyclopedia of Life Sciences (ELS), John Wiley \& Sons, Chichester, UK (2010).

8- Du, Q., Jerz, G. and Winter halter, P. Isolation of two anthocyanins sambubiosides from bilberry (Vacciniummyrtillus) by high-speed countercurrent chromatography, J. Chromatography A, 1045, (1-2), 59-63 (2004).

9- Kirca, A. Ozkan, M. and Cemeroglu, B. Storage stability of strawberry jam color enhanced with black carrot juice concentrate, J. Food Processing and Preservation, 31(5), 531-545 (2007).

10- Tian, Q., Aziz, R. M., Stoner, G. D., and Schwartz, S. J., Anthocyanin determination in black raspberry (Rubusoccidentalis) and biological specimens using liquid hromatography electrospray ionization tandem mass spectrometry, J. Food Science, 70(1), C43-C47 (2005).

11- Wang, X., Tong, H., Chen, F., and Gangemi, J. D., Chemical characterization and antioxidant evaluation of muscadine grape pomace extract, Food Chemistry, 123(4), 1156-1162 (2010).

12- Murapa, P., Dai, J., Chung, M., Mumper, R. J., and D'Orazio, J., Anthocyanin-rich fractions of blackberry extracts reduce UV induced free radicals and oxidative damage in keratinocytes, Phytotherapy Research, (1), 106-112 (2012).

13- Nazeeruddin M. K., Kay A., Rodicio I., HumphryBaker R., Muller E., Liska P., Vlacho-poulos N., Gratzel M., Conversion of light to electricity by cisX2bis(2,2'-bipyridyl-4,4'-dicarboxylate) ruthenium(II) charge-transfer sensitizers ( $\mathrm{X}=\mathrm{Cl}$-, $\mathrm{Br}-$, I-, CN-,and SCN-) on nanocrystalline titanium dioxide electrodes", J. Am. Chem. Soc., 115, 63826390(1993).

14- Roy M.S., Balraju P., Kumar M., Sharma G.D., Dye-sensitized solar cell based on Rose Bengal dye and nanocrystalline TiO2, Sol. Ener. Mat., 92, 909(2008).

15- Brian, E. H., Henry J. S, Michael D. M., The renaissance of dye-sensitized solar cells, Nature Photonics 6, 162-169(2012).

16- Qingjiang, Y., Yinghui, W., Zhihui, Y., Ningning Z., Jing Z., Min Z., and Peng W., High-Efficiency Dye-Sensitized Solar Cells: The Influence of Lithium Ions on Exciton Dissociation, Charge Recombination, and Surface States, ACS Nano, $4(10), \quad 6032-$ 6038(2010).

Arab J. Nucl. Sci. \& Applic. Vol. 51, No. 3 (2018) 
17- Meidan, Y., Xiaoru, W., Mengye, W., James, I., Nan, Z., Changjian. L., Zhiqun, L., Recent advances in dye-sensitized solar cells: from photoanodes, sensitizers and electrolytes to counter electrodes, Materials Today, 18, 3 (2015).

18- Zhang, G., Bala, H., Cheng, Y., Shi, D., Lv, X., Yu, Q., Wang, P., High efficiency and stable dyesensitized solar cells with an organic chromophore featuring a binary $\pi$-conjugated spacer, Chem. Commun.,23,.2198-2200(2009).

19- Agnes, M., Isaiah, O., Balla, D. N., Bonex, M., Simon, M. D., Park, E., Malik, M., Natural Dye Sensitizer for Grätzel Cells: Sepia Melanin", Physics and Materials Chemistry, 3(1), 1-6(2015).

20- Sullivan, J., Anthocyanin, ICPS, News letter (1998).

21- Goto, T., Kondo, T., Structure and molecular stacking of anthocyanins: flower color variation, Angew. Chem. Int. Ed. Engl, 30, 17(1991).

22- Heredia, F.J., Francia-Aricha, E.M., RivasGonzalo, J.C., Vicario, I.M., Santos-Buelga, C., Chromatic characterization of anthocyanins from red grapes - I. PH effect, Food Chem., 63, 491(1998).

23- Harborne, J. B., Spectral methods of characterizing anthocyanins, Biochem. J., 70, 22-28(1958).

24- Jarkko, E., Comparison of three Finnish berries as sensitizers in a dye-sensitized solar cell, European Journal for Young Scientists and Engineers, 1(2012).

25- Jungmin, L., et al., Determination of total monomeric anthocyanine pigment content of fruit juices, beverages, natural colorants, and wines by the $\mathrm{pH}$ differential method: Collaborated study, Journal of AOAC International, 88 (5), 1269(2005).

26- Giusti, M.M., Wrolstad, R.E., Anthocyanins characterization and measurement with UV visible spectroscopy, In R. E. Wrolstad (Ed.), Current Protocols in Food Analytical Chemistry, New York: Wiley, Unit F1.2., 1-13(2001).
27- Fuleki, T. and Francis, F. J., Quantitative methods for anthocyanins. 1. Extraction and determination of total anthocyanin in cranberries, J. Food Science, 33, (1) 72-77(1968).

28- Fuleki, T.and Francis, F. J., Quantitative methods for anthocyanins. 2. Determination of total anthocyanin and degradation index for cranberry juice, J. Food Science, 33, (2) 78-83(1968).

29- Ronald, E. W., Robert, W. D. and Jungmin, L., Tracking color and pigment changes in anthocyanin products, Trends in Food Science \& Technology $16,423-428(2005)$.

30- Bayram, G., Effects of molarity and solvents on the optical properties of the solutions of tris[4-(5dicyanomethylidenemethyl-2-thienyl)phenyl]amine (TDCV-TPA) and structural properties of its film, Optical Materials 36, 425-436(2013).

31- Tauc, J., Grigorovici, R., Vancu, A., Optical Properties and Electronic Structure of Amorphous Germanium, Phys. Status Solidi, 15, 627(1966).

32- Syafinar, R., Gomesh, N., Irwanto, M., Fareq, M., Irwan, Y. M., Optical characterization using nature based dye extracted from Hibiscus's flower, ARPN J. Engineering and Applied Sciences, 10, 15(2015).

33- Sulaiman, K. and Fakir, M.S., Electrical conduction and photovoltaic effects of TPA derivative solar cells, Thin Solid Films 519, 5219-5222(2011).

34- Peter, A. and De P. J., Physical Chemistry, 9th ed., Oxford: Oxford UP (2010).

35- Lawrence, A., Shaichi, S. J., Asif, A., Nikia, B., Sunil, Y., Destiny, B., William, G., Alec, G., Mintesinot, J., Jamal, U., Creation of Natural Dye Sensitized Solar Cell by Using Nanostructured Titanium Oxide, Nanoscience and Nanoengineering 3 (3), 25-32(2015).

36- Lin, H., Huanga, C.P., Li, W., Ni, C., Shah, S.I., Yao-Hsuan, T., Size dependency of nanocrystalline $\mathrm{TiO} 2$ on its optical property and photo-catalytic reactivity exemplified by 2-chlorophenol, Applied Catalysis B: Environmental , 68,1-11(2006). 